\title{
ACOUSTIC Signaling IN SAgebRUSH CRICKETS: A TeST OF THE TERRITORIAL HYPOTHESIS
}

\author{
KRISTIN A. PETERSEN $\bullet$ ANNE-KATRIN EGGERT \\ MICHAEL W. WILl $\downarrow$ SCOTT K. SAKALUK \\ ECOLOGY GROUP • DEPARTMENT OF BIOLOGICAL SCIENCES \\ ILLINOIS STATE UNIVERSITY $\bullet$ NORMAL
}

\section{$\checkmark \quad$ INTRODUCTION}

The sagebrush cricket, Cyphoderris strepitans, is one of only five extant species belonging to an ancient insect lineage, the Haglidae, believed to be ancestral to modern-day crickets and katydids (Orthoptera: Ensifera) (Morris and Gwynne 1978). C. strepitans occurs exclusively in mountainous areas of Wyoming and Colorado, where it is found primarily in high-altitude sagebrush meadow habitat. Adults become sexually active in May, shortly after snowmelt, and remain active for the next 4-6 weeks. Each night of the breeding season, males emerge from the soil litter shortly after sunset, climb into the sagebrush and begin to sing, presumably to attract sexually receptive females. Copulation is initiated when a receptive female climbs onto the dorsum of a male, at which time he attempts to transfer a spermatophore. During copulation, the female feeds on the male's fleshy metathoracic wings and ingests any haemolymph leaking from the wounds she inflicts (Sakaluk et al. 1987, Morris et al. 1989, Sakaluk and Snedden 1990). The wounds that result from wing feeding provide a convenient, permanent record of a male's mating status; through visual inspection of the metathoracic wings, it is possible to determine whether field-collected males are virgin or have mated at least once prior to their capture (Dodson et al. 1983, Morris et al. 1989).
Pair formation in crickets usually is mediated through acoustic signaling by males, which functions to attract sexually receptive females (reviewed by Cade 1979). We have been unable, however, to demonstrate phonotaxis of female $C$. strepitans in standard behavioral assays. There are at least two hypotheses which could account for the observed lack of female responsiveness: 1) females are not phonotactic, but instead located males via other signaling modalities (e.g., olfaction), and 2) females are phonotactic, but the experimental protocol employed in previous laboratory studies was inadequate to detect such a response. With respect to the latter possibility, it may be that females respond only under test conditions which closely approximate the field environment or, alternatively, that elicitation of a female response requires an extended period of auditory stimulation that exceeds the short response latencies expected of females in standard phonotaxis experiments.

To more fully explore the hypothesis that females use the sounds of males to locate males as mates, a mark-recapture study was conducted in May-June 1990, in which the subsequent mating success of experimentally muted males was compared with that of males in a sham-control group. This field experiment showed a marked decrease in the fitness of experimentally muted males, a result that can be interpreted as evidence of female phonotaxis 
(Snedden and Sakaluk, in review). Alternatively, male calling theoretically could function as a territorial signal to other males, with females attracted to males via some other signaling modality. It could be argued, therefore, that the decline in fitness of muted males arose from their inability to exclude rivals, rather than an inability to attract females. The objective of the present study was to test the hypothesis that acoustic signaling by male sagebrush crickets functions to exclude rival males, thereby facilitating increased male mating success. We tested this hypothesis by comparing the mating success of males experimentally hindered from defending a territory with that of control males.

\section{$\checkmark \quad$ METHODS}

\section{MARK-RECAPTURE STUDY}

The territorial hypothesis predicts that males unable to detect the acoustic signals of their rivals would be at a selective disadvantage because such males would inadvertently trespass on the territories of their competitors and/or be unable to detect rivals present on their own territories. To test this prediction, a mark-recapture study was conducted in June 1991 near the Snake River at Deadman's Bar in Grand Teton National Park. Four corners of a rectangular study plot $(90 \mathrm{~m} \times 60 \mathrm{~m})$ were staked out in relatively homogeneous, sagebrush-meadow habitat on a bench of the river's flood plain. During an initial sampling period (June 1-7, 1991), we attempted to capture and mark all of the virgin males present in the study plot. Perching locations of males were found by orienting to the acoustic signals produced by individual males and then searching the sagebrush with the aid of a headlamp. Mating status (virgin or non-virgin) of individual males was ascertained by inspection of their hind wings. Nonvirgin males were released at their point of capture immediately after their mating status has been ascertained. Virgin males were placed in individually numbered vials and transported back to the UW-NPS Research Center, approximately $30 \mathrm{~km}$ away, where they were processed. Capture sites of individual males were flagged with surveyor's stakes, numbered to correspond with the collecting vials. The following morning, virgin males were transported back to the study site and released at their flagged capture sites, thereby preserving the original distribution of males.
Captured males were sequentially assigned, in order of their capture, to one of three experimental groups: 1) experimentally deafened, 2) sham control, and 3) unmanipulated. Sequential assignment of males ensured that a comparable number of males in each group were marked on any one night, and that subsequent mating opportunities were equivalent across treatments. Experimental males were rendered deaf by rupturing their tympanic membranes with an entomological pin; an anterior and posterior tympanic membrane occur on both forelegs. The hindlegs of sham-treated males were punctured at similar locations. Unmanipulated controls were physically handled during marking, but were otherwise left unaltered. Each male was marked individually with a numbered plastic tag attached to the pronotum with cyanoacrylic glue. Additionally, fluorescent paint was applied to the pronotum around the tag, and to the hind femora of each male. In total, we tagged and released 77 virgin males (26 deafened, 25 sham-control, 26 unmanipulated).

After the first group of males had been processed and released, males were re-captured and examined for evidence of mating activity every second night over the course of the breeding season. Recapture of experimental males was enhanced by scanning the sagebrush and ground with portable UV lights, the illumination of which causes the painted pronota of experimental males to brightly fluoresce. Unmarked virgin males detected in subsequent censuses were transported to the field station and processed according to standard procedures. To determine the average nearest-neighbor distance of males in each treatment, a numbered surveyor's flag was placed at the capture site of each male and that of his nearest calling neighbor. Nearest-neighbor distances were determined the following day using a Sonin $\mathbf{R}$ ultrasonic measuring device, accurate to 0.01 m. We also recorded the following data for each male captured: 1) mating status, as determined by the condition of the hindwings (intact $=$ virgin, wounded = non-virgin), 2) whether the male was marked (experimental) or unmarked (non-experimental), 3) tag number (if marked) and 4) the number of the flag placed at each male's capture site.

\section{CALLING DURATIONS OF EXPERIMENTAL MALES}

To control for the possibility that the calling behavior of deafened males is influenced by their 
inability to hear, nightly calling durations of treated males were monitored using an electronic sound-relay apparatus (Kidder \& Sakaluk 1989). Males were captured at a site adjacent to the mark-recapture study area, and transported to the UW-NPS Research Center. Three males were monitored each night, one from each of the above treatments.

Each male was housed in a uniquely labeled cage, appropriately ventilated and with an opening through which a microphone was inserted. Approximately $10 \mathrm{~cm}$ of soil litter was placed on the bottom of the cage to provide cover for males during the day, and a slice of apple added as a source of food and water. A sprig of sagebrush was inserted into the litter of each cage to provide a perch from which the male could call at night. Cages were separated by at least $1.5 \mathrm{~m}$, within the range of normal inter-male distances. Electronic monitoring of acoustic signaling commenced on the second night following capture, to allow sufficient time for males to acclimate to their new surroundings, and continued until the following morning. In total, we monitored the singing activity of $\mathbf{3 1}$ males over the course of the study.

\section{$\checkmark \quad$ RESUltS}

\section{MARK-RECAPTURE STUDY}

Forty-seven tagged males ( $61 \%$ of all marked males) were recaptured at least once, and recapture frequencies were homogeneous across treatments $\left(\mathrm{X}^{2}\right.$ $=0.48, P=0.79)$. There was no significant difference in the proportion of males that mated across experimental treatments (Fisher's Exact Test, $P=0.449$ ). As a separate measure of male mating success, we also determined the time elapsed from the release of each male to the first observed evidence of mating (Table 1.) There was no difference in the time taken by males to secure their first copulation across experimental treatments (ANOVA, $\mathrm{F}=0.17, \mathrm{P}>0.05$ ). We conclude, therefore, that deafened males are not hindered in their ability to secure matings.

A two-way mixed model ANOVA was used to compare nearest-neighbor distances across treatments, with treatment as the fixed effect and sampling night as the random effect. Nearest-neighbor distances were square-root transformed to render them suitable for parametric analysis. Although average nearestneighbor distances varied significantly from night to night $(F=28.3, P<0.0001)$, nearest-neighbor distances were uninfluenced by the treatment to which males belonged $(F=2.20, P>0.05)$. The average-nearest neighbor distance of all males at peak density (June 11, 1991) was compared with the average distance expected under a random distribution (Clark and Evans 1954); the spatial distribution of males did not deviate significantly from randomness $(R=0.886, P>0.05)$.

\section{CALLING DURATIONS OF EXPERIMENTAL MALES}

Preliminary analyses revealed no significant effects of mass, sampling date or average nightly room temperature on male calling duration. There were also no significant differences across treatments in the mean nightly calling durations of males (Table 2; Kruskal-Wallis, $\mathrm{X}^{2}=0.81, \mathrm{P}>0.05$ ).

Table 1. Average time elapsed from initial release to copulation in male $C$. strepitans.

\begin{tabular}{llcl}
\hline Treatment & $\mathrm{N}$ & "Mean(nights) & $\mathrm{SD}$ \\
\hline Deaf & 11 & 4.45 & 2.34 \\
Sham-Control & 12 & 4.42 & 3.70 \\
Unmanipulated & 12 & 3.83 & 2.29 \\
& & & \\
\hline${ }^{*} \mathrm{~F}=0.17, \mathrm{P}>0.05$ & & \\
\hline
\end{tabular}

Table 2. Mean nightly calling durations of male $C$. strepitans.

$\begin{array}{lll}\text { Treatment } & \text { N "Mean (min) SD }\end{array}$

$\begin{array}{llll}\text { Deaf } & 10 & 71.6 & 68.6 \\ \text { Sham-Control } & 11 & 31.4 & 53.6 \\ \text { Unmanipulated } & 11 & 57.6 & 78.9\end{array}$

Kruskal-Wallis, $\mathrm{X}^{2}=0.81, \mathrm{P}>0.05$ 


\section{$\checkmark \quad$ CONCLUSIONS}

Deafened males, since they are unable to respond to calling rivals, should have a reduced ability to maintain exclusive broadcast areas. If the ability to maintain a territory is important in securing access to potential mates, deafened males should experienced reduced mating success. In our study, however, the mating success of deafened males did not differ significantly from that of sham-operated or unmanipulated males.

The territorial hypothesis also predicts that the nearest-neighbor distances of deafened males should be significantly shorter than those of sham-operated males. This prediction is based on the premise that deafened males should frequently be at risk of intruding inadvertently into the broadcast space of rival males. Depending on whether the resident male is able to hear or has been deafened, there are two possible outcomes of such an interaction: hearing residents would be expected to exhibit negative phonotaxis to calling intruders and thereby regain an exclusive broadcast area, whereas deafened residents would be expected to remain oblivious to intruders and exhibit no locomotory response. However, our results showed no significant differences in the average nearest-neighbor distances across treatments. Moreover, the observed distribution of all males at peak density did not deviate significantly from randomness. These results suggest that calling does not in any meaningful way mediate the spatial distribution of males. We conclude, therefore, that acoustical signaling in sagebrush crickets does not function in territorial maintenance.

\section{$\checkmark$ ACKNOWLEDGEMENTS}

We thank M. Boyce and G. Plumb for logistic support, S. Juliano for statistical advice, and Earthwatch volunteers for their able assistance in the field. The study was supported by grants from the University of Wyoming-National Park Service Research Center and the Earthwatch Foundation to S.K.S. and W.A. Snedden, a grant from Illinois State University to S.K.S., grants from Phi Sigma (Beta Lambda Chapter) and the ISU Graduate Student Association to K.A.P., and a post-doctoral fellowship from the Deutsche Forschuingsgemeinschaft to A.K.E.

\section{$\checkmark \quad$ LITERATURE CITED}

Cade, W.H. 1979. The evolution of alternative male reproductive strategies in field crickets. In M.S. Blum and N.A. Blum, eds. Sexual Selection and Reproductive Competition in Insects. Academic Press, NY. pp. 343-379.

Clark, P.J. and F.C. Evans. 1954. Distance to nearest neighbor as a measure of spatial relationships in populations. Ecol. 35: 445-453.

Dodson, G.N., G.K. Morris and D.T. Gwynne. 1983. Mating behavior of the primitive orthopteran genus Cyphoderris (Haglidae). In: Orthopteran Mating Systems: Sexual Competition in a Diverse Group of Insects, ed. by D.T. Gwynne and G.K. Morris. pp. 305-318. Westview Press, Boulder, CO.

Kidder III, G.W., and S.K. Sakaluk. 1989. A simple and inexpensive electronic device for automatic recording and analysis of insect acoustical activity. Fla. Entomol. 72: 642-649.

Morris, G.K., and D.T. Gwynne. 1978. Geographical distribution and biological observations of Cyphoderris (Orthoptera: Haglidae) with a description of a new species. Psyche 85: 147-167.

Morris, G.K., Gwynne, D.T., Klimas, D.E., and S.K. Sakaluk. 1989. Virgin male mating advantage in a primitive acoustic insect (Orthoptera: Haglidae). J. Insect Behav. 2: 173185.

Sakaluk, S.K., Morris, G.K., and W.A. Snedden. 1987. Mating and its effect on acoustic signalling behavior in a primitive orthopteran, Cyphoderris strepitans (Haglidae): the cost of feeding females. Behav. Ecol. Sociobiol. 21: 173-178.

Sakaluk, S.K., and W.A. Snedden. 1990. Nightly calling durations of male sagebrush crickets, Cyphoderris strepitans: size, mating and seasonal effects. Oikos 57: 153-160.

Snedden, W.A., and S.K. Sakaluk. in review. Acoustical signalling and its relation to male mating success in sagebrush crickets. submitted to Anim. Behav. 